\title{
STAKEHOLDER ENGAGEMENT IN COASTAL SUSTAINABILITY TRANSITIONS: AN EMERGING RESEARCH AGENDA
}

\author{
Dr. Stephen Axon ${ }^{1}$, Dr. Anya Chapman ${ }^{2}$ and Dr. Duncan Light ${ }^{2}$ \\ ${ }^{1}$ School of Natural Sciences and Psychology, Liverpool John Moores University, \\ Byrom Street, Liverpool, L3 3AF, United Kingdom. \\ 2 Faculty of Management, Bournemouth University, Dorset House, Talbot Campus, \\ Fern Barrow, Bournemouth, BH12 5BB, United Kingdom.
}

\section{Sustainability Transitions at the Coast and the role of stakeholder engagement}

In this short paper we consider the issue of sustainable transitions in the coastal zone with particular reference to renewable energy projects. While there has been considerable debate about sustainability transitions and the need for stakeholder engagement within such projects, much research to date has neglected coastal areas. This is surprising given that the coastal zone is particularly susceptible to the impacts of climate change, and much policy attention towards establishing new renewable energy projects are focused on coastal areas. While the development of renewable energy projects in coastal areas have numerous advantages for supporting a sustainable transition, such projects need to engage numerous stakeholders and users to increase their acceptability and legitimacy. In the UK, there are around 6.2 million people (equating to $11 \%$ of the population) living at the coast (Office for National Statistics, 2014). Furthermore, tourists who visit these areas are a significant part of the economy of coastal areas: in 2016, there were over 21 million staying visitors to the coast, and a further 106 million domestic day visits (National Coastal Tourism Academy 2016). These diverse communities and users all represent stakeholders who are potentially impacted by sustainable energy projects. Therefore, the views and attitudes of these users need to be taken into account when developing renewable energy projects at the coast. To achieve this, clear pathways of engagement are required to ensure that projects are a success. Yet there is often little public engagement with sustainability transitions. Instead decisions on such projects are frequently made in a top-down manner with the result that sustainability initiatives may be poorly understood and so lack popular support. Therefore a rethink of the practice of public engagement within sustainability transitions at the coast is essential.

Public engagement with renewable energy projects at the coast can take a wide variety of forms. These can be conceptualised as a continuum ranging from passive consultation through to active participation. Passive consultation simply involves the communication of information to actual or potential stakeholders, but with little consideration of their responses. More active approaches to consultation might involve directly responding to stakeholder feedback and encouraging stakeholders to directly participate in the development process. For example, guided tours can be used to illustrate the nature and character of sustainability transitions at the coast, with the aim of increasing understandings of sustainability initiatives and developing support for renewable energy projects. At another level is active participation by stakeholders which might involve interactive workshops, focus groups and role play exercises. Stakeholders might also be invited to join decision-making panels. Furthermore, stakeholders can be encourage to form (and volunteer for) community 
groups that are attached to (and input into) the renewable energy project. Such deeper participation has the potential to create partnerships to take a project forward.

In general terms, the more intense the engagement the fewer people are involved. Passive consultation involves a large number of people receiving information (but not acting on it) while participation will involve fewer people, but engaging with the project at a much deeper level. An effective engagement exercise should aspire to embracing the full range of stakeholders, underpinned by a recognition that passive consultation alone is not sufficient to achieve stakeholder engagement.

Furthermore, effective stakeholder engagement with sustainable transition projects at the coast should start at an early stage and should be designed as a long-term process. In practice this means that engagement and consultation should last longer than the statutory minimum time required by the Department of Communities and Local Government and the Planning Inspectorate. A prolonged period of consultation and engagement allows for the identification of all stakeholders who may be affected by a renewable energy project. This includes those who are directly impacted (such as local residents and businesses) and those who are indirectly involved (such as tourists and leisure users). An effective process will aim to identify the needs and wants of all stakeholders, a process termed stakeholder analysis. Undertaking stakeholder analysis enables an engagement process that is bottom-up in nature. Following these initial consultations a range of project options can be proposed (which will take account of the needs of a diverse range of stakeholders). At this stage, information presented must be both accessible to stakeholders and transparent. Further feedback can identify which option is most acceptable and attractive to stakeholders, enabling the development of a final proposal which will enjoy maximum stakeholder support. Engaging stakeholders (whether individuals or collectives) in this way can prevent apathy and non-involvement. In this way, issues surrounding energy and sustainability in coastal areas can be brought to the fore through framing them, and allowing individuals to act upon them, within the contexts of where people live, work, travel to, shop, consume, and play.

\section{Stakeholder engagement in renewable energy projects: Two case studies of recent practice}

In 2011 a partnership between Dutch and French energy companies put forward plans for a substantial offshore windfarm - named Nativus Bay - located off the coast of Bournemouth in southern England. Following the proposal there was an 18 month period of public consultation. This was relatively passive in approach, being centred around presentations of the project or drop-in sessions. The local authority and local businesses had serious concerns about the impact of the windfarm on the visitor economy of Bournemouth and the surrounding area, particularly since tourism has long been a significant component of Bournemouth's economy. In response to public consultation the size of the windfarm was modified: the number of turbines was reduced from 333 to 194, the total surface area was also reduced, and the height of the turbines was also modified. However, the developers were accused of misleading the public by under-representing the wind farm's visual impact and its socio-economic impact during the period of construction (Gosden 2014). Mistrust among stakeholders meant that the project failed to gain local support and in September 2015 it was rejected by the Planning Inspectorate. Navitus Bay can be interpreted as a top-down project, involving limited consultation with local stakeholders, and which did not 
succeed in winning hearts and minds in the area that would be impacted by the proposal.

A second example is Swansea Bay Tidal Lagoon in Wales, and this is noteworthy for its extensive stakeholder consultation and participation. Consultation (involving over 400 meetings with stakeholders) started in 2011, well before concrete proposals were put forward. A series of options was put forward in 2012, but the statutory process of consultation started only in 2013. Stakeholder engagement went beyond passive consultation and instead aimed for active participation. In particular, four supporters groups (totalling 1000 members) were organised and run by volunteers. These participated in engagement events to provide a stakeholder perspective to other stakeholders (particularly local communities). Engagement also focussed on education, ranging from primary school level (in the form of workshops on climate change and renewable energy) through to university level (through providing access to Masters students to consultancy projects with local businesses). As a result local communities fully understood the social and economic benefits of the proposal, so that the tidal lagoon project enjoyed widespread popular support. In January 2017 the proposal was backed by a government review (although government funding for the lagoon has yet to be confirmed)

\section{Bridging theory, policy and practice: Implications for low-carbon transitions at the coast}

Current policy in the UK is increasingly focussing on the coastal zone as the location for renewable energy projects. Yet, what is frequently overlooked is the impacts of such projects on local communities and (often fragile) local economies. It is clear that sustainable energy projects will only enjoy support by coastal communities if a wider social and economic benefit can be demonstrated. In practice this means that renewable energy projects need to be more than just sustainability. Instead, they have to address the specific needs and requirements of stakeholders, within specific local contexts. This points to the need for extensive engagement with local stakeholders and communities. Developers need to move beyond tokenistic consultation and instead embrace a more 'bottom up' approach which allows stakeholders, users and communities to envision the wider social and economic benefits of such projects. The larger the project, the longer (and deeper) the period of engagement needs to be. Ultimately, sustainable transitions at the coast need to aspire to creating shared value (see Porter and Kramer 2011) that generates economic value, whilst also producing value for local communities and stakeholders. Moreover, local stakeholders can be active co-creators in the process. Future research and practice should now seek to identify clear pathways of engagement with coastal communities, while renewable energy projects themselves need to encompass more than just sustainability dimensions and incorporate activities that address, economic and social issues specific to those communities.

\section{References}

Gosden, E. (2014) Developer 'misled public' over controversial wind farm off the Isle of Wight, Daily Telegraph 13 April. Accessed from: http://www.telegraph.co.uk/news/earth/energy/10761676/Developer-misled-publicover-controversial-wind-farm-off-Isle-of-Wight.html on 1 May 2017.

National Coastal Tourism Academy (2016) 2016 Coastal Tourism, Bournemouth: 
National Coastal Tourism Academy

Office for National Statistics (2014) 2011 Census: Coastal Communities, Newport: Office for National Statistics.

Porter, M.E. \& Kramer, M.R. (2011) Creating Shared Value, Harvard Business Review, 89 (1-2): 62-77.

Sale, P.F., Agardy, T., Ainsworth, C.H., Feist, B.E., Bell, J.D., Christie, P., Hoeghguldberg, O., Mumby, P.J., Feary, D.A., Saunders, M.I., Daw, T.M., Foale, S.J., Levin, P.S., Lindeman, K.C., Lorenzen, K., Pomeroy, R.S., Allison, E.H., Bradbury, R.H., Corrin, J., Edwards, A.J., Obura, D.O., Sadovy, Y.J., Mitcheson, D., Samoilys, M.A. and Sheppard, C.R.C. (2014) Transforming management of tropical coastal seas to cope with challenges of the 21st century. Marine Pollution Bulletin, 85: 8-23. 